\title{
A Modern Approach to Endometrial Carcinoma: Will Molecular Classification Improve Precision Medicine in the Future?
}

\author{
Simone Marnitz ${ }^{1,2, *}$, Till Walter ${ }^{1,2}$, Birgid Schömig-Markiefka ${ }^{2,3}$, Tobias Engler ${ }^{4}$, \\ Stefan Kommoss ${ }^{4}$ and Sara Yvonne Brucker $4, *$ (D) \\ 1 Department of Radiation Oncology, CyberKnife and Radiotherapy, Medical Faculty University Cologne, \\ 50937 Cologne, Germany; till.waltar@uk-koeln.de \\ 2 Center of Integrated Oncology Cologne Bonn (CIO), 53127 Bonn, Germany; birgid.markiefka@uk-koeln.de \\ 3 Institute of Pathology, Medical Faculty University Cologne, 50937 Cologne, Germany \\ 4 Department of Women's health, University Hospital Tuebingen, 72076 Tuebingen, Germany; \\ tobias.engler@med.uni-tuebingen.de (T.E.); stefan.kommoss@med.uni-tuebingen.de (S.K.) \\ * Correspondence: simone.marnitz-schulze@uk-koeln.de (S.M.); sara.brucker@med.uni-tuebingen.de (S.Y.B.)
}

Received: 30 July 2020; Accepted: 30 August 2020; Published: 10 September 2020

Simple Summary: The scientific community widely agrees that molecular classification will be key to endometrial carcinoma therapeutic strategies in the future. Retrospective analyses of large endometrial carcinoma patient cohorts gave rise to a new understanding of one of the most relevant gynecologic malignancies. Potentially replacing the current type I and type II terminology, four molecular subtypes have been established, each of them reflecting underlying molecular aberrations and distinct clinical behavior. Future research will have to focus on how to integrate these new findings into clinical practice with the ultimate goal to drive personalized endometrial carcinoma patient care forward.

\begin{abstract}
Endometrial cancer has been histologically classified as either an estrogen-dependent cancer with a favorable outcome or an estrogen-independent cancer with a worse prognosis. These parameters, along with the clinical attributions, have been the basis for risk stratification. Recent molecular and histopathological findings have suggested a more complex approach to risk stratification. Findings from the Cancer Genome Atlas Research Network established four distinctive genomic groups: ultramutated, hypermutated, copy-number low and copy-number high prognostic subtypes. Subsequently, more molecular and histopathologic classifiers were evaluated for their prognostic and predictive value. The impact of molecular classification is evident and will be recognized by the upcoming WHO classification. Further research is needed to give rise to a new era of molecular-based endometrial carcinoma patient care.
\end{abstract}

Keywords: endometrial cancer; uterus carcinoma; molecular classification; risk classification; risk stratification; adjuvant radiation; brachytherapy; POLE; L1CAM; MMRd

\section{Introduction}

For many decades, endometrial cancer has been considered a tumor entity with a favorable outcome and two distinct types: Type 1, estrogen-dependent with a better prognosis, and Type 2, non-estrogen-dependent with a worse prognosis [1]. Endometrial carcinomas (ECs) are typically diagnosed at an early stage and have more favorable outcomes; however, between 15-20\% of women will relapse and eventually die from their disease. Identifying which patients are at risk for recurrence may be challenging; consequently, under- and overtreatment remain clinical issues. Endometrial 
carcinoma is the most common gynecological malignancy, and progress in accurate and reliable categorization is eagerly awaited.

\subsection{Current Risk Stratification}

Based on tumor type, stage, grade and lymphovascular space invasion (LVSI) current endometrial carcinoma treatment guidelines (ESMO-ESGO-ESTRO 2016 Consensus) stratify patients into four distinctive groups: low-, intermediate-, high-intermediate- and high-risk disease [2-5]. Treatment decisions and patient guidance have been tailored to the latter risk groups. However, comparison of treatment recommendations may be difficult since the international scientific community has used different risk classifications in the past and has not yet been able to implement a standardized classification system [6-10] (Figure 1).

\begin{tabular}{|c|c|c|c|c|}
\hline \multirow{4}{*}{ 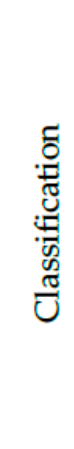 } & Low & Intermediate & $\begin{array}{c}\text { High } \\
\text { intermediate }\end{array}$ & High \\
\hline & \multirow{3}{*}{$\begin{array}{c}\text { Type I } \\
\text { FIGO IA } \\
\text { G1/G2 }\end{array}$} & \multirow{3}{*}{$\begin{array}{c}\text { Type I } \\
\text { FIGO IB } \\
\text { G1/G2 }\end{array}$} & $\begin{array}{c}\text { Type I } \\
\text { FGO IA } \\
\text { G3 }\end{array}$ & $\begin{array}{l}\text { Type I } \\
\text { FIGO IB } \\
\text { G3 }\end{array}$ \\
\hline & & & \multirow{2}{*}{$\begin{array}{c}\text { Type I } \\
\text { FIGO IA/B } \\
\text { G1/G2 } \\
\text { LVSI pos. }\end{array}$} & Type II \\
\hline & & & & FIGO $>$ I \\
\hline ผั & $93.4 \%$ & $86.3 \%$ & $82 \%$ & $<74 \%$ \\
\hline \multirow{6}{*}{ 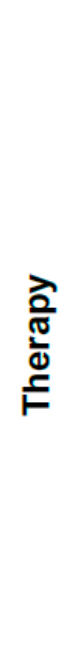 } & \multicolumn{4}{|c|}{ Hysterectomy \& Adnexectomy/Salpingectomy } \\
\hline & & \multicolumn{2}{|c|}{ Lymphonodectomy } & \\
\hline & & & & $\begin{array}{c}\text { Cytoreductive } \\
\text { surgery }\end{array}$ \\
\hline & & \multicolumn{3}{|c|}{ Brachytherapy } \\
\hline & & & & Teletherapy \\
\hline & & & & Chemotherapy \\
\hline
\end{tabular}

Figure 1. Current recommendations on risk stratification and therapy based on classical clinical risk factors and five-year overall survival (modified from AGO S3-Guideline).

\subsection{Limitations of Clinical Risk Factors}

Furthermore, indication for more extensive surgery besides hysterectomy with bilateral salpingo-oophorectomy (BSO) depends on factors that are often unknown or unclear preoperatively (i.e., myometrial infiltration). These preoperative uncertainties lead to either undertreatment with subsequent second surgery or the risk of overtreatment. Maximum tumor size and myometrial 
infiltration can be determined using intraoperative frozen sections, which are not available everywhere [9,11]. Of course, if future treatment also depends on increasingly complex analyses like molecular classification, there is a need for centralization of the diagnostic procedure and even the gynecological cancer treatment. The German Cancer Aid and the National Cancer Plan are working together with cancer societies with the overall goal to centralize cancer patient treatment and to provide care to a reasonable number of patients per year with a multidisciplinary team of specialists. This is a "conditio sine qua non".

Moreover, the validity of clinical risk factors is often limited by a large interobserver variability in conventional pathology with regard to LVSI and grading, which could also be different from the result of the biopsy taken by curettage to the uterus specimen. The re-evaluation by a central pathology, compared to the results of a local pathology, demonstrated a considerable shift in grading EC patients that impacts the reliability of an adjuvant treatment recommendation [10,12].

Lymph node metastases $(\mathrm{pN}+)$ are considered a major risk factor and are the most important prognostic factor and determinator for adjuvant therapy in patients with EC.Moreover, most primary ECs are confined to the uterus, and only about $10 \%$ will have pelvic lymph node metastasis [13]. However, as a result of the ASTEC and Italian trial $[14,15]$, there has been a decreasing rate of lymphadenectomies (LNs) worldwide. As a consequence, FIGO stage III cannot be subdivided into stage III C1 and C2 in many patients, which makes the interpretation of study results difficult (please see the section below) [16-18].

Although not validated in randomized studies, there is an increasing use of the sentinel node technique (SLN) in endometrial cancer patients, taking into account that the SLN minimizes radicality but could also maximize the accuracy of the staging and tumor stage, as up to $20 \%$ of positive SLNs are atypically located and could therefore be missed by conventional LNs. Immunohistochemistry in combination with ultrastaging of sentinel lymph nodes leads to a dramatic increase in detection of isolated tumor cells (ITCs) and micrometastases (MICs). For adjuvant treatment recommendations, the SLN raises new questions. ITCs and MICs now account for $50 \%$ of the positive findings after ultrastaging in EC patients [19]. The impact of ITCs on prognosis is a topic of ongoing discussion. MICs lead to a significantly worse prognosis and are considered as $\mathrm{pN}+$ disease (lymph node metastases) and therefore lead to an increased rate of adjuvant treatment as a result of SLN [19-23]. These results were underlined by the FIRES trial. It was demonstrated that $54 \%$ of the patients with positive sentinel lymph nodes had lymph node disease identified only with ultra-staging. This results in $>50 \%$ of adjuvant treatment indications compared to cohorts only after conventional histology. Sixty percent of the FIRES patients with positive SLN had disease limited to the sentinel lymph nodes. Seventeen percent of the patients had positive sentinel lymph nodes that were found exclusively in regions lying outside of a routine lymphadenectomy. This should lead to rethinking a target volume definition for radiation [24]. However, despite more frequent use of adjuvant therapy following sentinel concept, a survival benefit has not yet been demonstrated until now [19-23].

Despite the supposedly differentiated clinical risk factors, the clinical impression remains that some patients classified as low-risk have an unfavorable course of the disease, while some patients with high risk factors show an impressively long progression-free survival. Until now, it has not been possible to predict such unexpected behavior; therefore, frequent follow-up visits are recommended for all patients, and under- and overtreatment remain daily routine practice obstacles. This solidified the impression that the usual clinical risk classification does not adequately depict tumor biology [25]. Furthermore, histotype and grade, the key parameters in the most popular stratification systems, have been shown to have a poor reproducibility [26-30], resulting in clinically relevant discrepancies. In terms of assessing treatment efficacy and refining these histopathological prognosticators, the low interobserver agreement has hampered research for many years. Moreover, stage and lymphovascular space invasion (LVSI), which are currently crucial for risk stratification, are only available after definitive surgery, leading to risk models that are unable to aid in decision making with regards to the extent 
of surgery. In contrast to more uniform treatment approaches of other gynecological malignancies, endometrial carcinoma management varies widely across international guidelines currently in use.

Therefore, new predictive tissue markers are warranted. Those markers could either be used alone or in combination with traditional clinico-pathological diagnostics to develop a preoperative nomogram to improve diagnostic accuracy and guide clinicians in their treatment decisions. This will minimize explorative lymph node staging surgery and clinically guide informed surgical treatment.

The need to address the above-mentioned challenges was recognized by the international research community, and remarkable progress has recently been made. Current literature provides new insights not only into tumor biology, but also into clinical risk stratification. Two major findings have changed the landscape of how we approach endometrial carcinoma today. In 2013, the Cancer Genome Atlas (TCGA) accomplished the most comprehensive molecular study yet in endometrial carcinoma, stratifying the entity in four distinctive subgroups: The "ultramutated" subgroup is characterized by a strong association with mutations in the exonuclease domain of polymerase- $\varepsilon$ (POLE) and also by an excellent prognosis. In addition to this intriguing subgroup, molecular profiling also identified a subgroup in which microsatellite instability (MSI) status was identified as a discriminating feature; a "copy-number high" subgroup with p53 mutations and a generally unfavorable course of disease and finally, the "copy-number low" subgroup. It has been suggested, that these molecular features may be used not only for patient classification and risk stratification but may also give rise to a more individualized guidance of surgery, adjuvant strategies and patient observation. However, the methods applied by TCGA were not feasible in a clinical context or single-patient setting. Inspired by these findings, molecular classifiers that are simplified, straightforward and easily applicable were developed, one of which is termed "ProMisE" (Proactive Molecular Risk Classifier for Endometrial Cancer) [31]. ProMisE identifies four molecular subtypes that are analogous but not identical to the four genomic subtypes described in TCGA. After development and confirmation, the classifier was validated in a large population-based series. The tool can be applied to standard formalin-fixed paraffin-embedded tissue using either endometrial biopsy or hysterectomy samples [32]. A similar assay has been established by the TransPORTEC international consortium, identifying very similar molecular subtypes with distinct outcomes and high diagnostic reproducibility $[33,34]$.

At the same time when TCGA classification was published, the L1 neuronal cell-adhesion molecule (L1CAM) gained attention as a specific prognosticator and potential therapeutic target in early-stage type I endometrial carcinoma [35,36]. Multiple studies have shown the prognostic significance of L1CAM immunohistochemistry (IHC) in large cohorts of endometrial carcinoma [37-40]. According to the findings, in low-risk endometrial carcinoma, it has been suggested to limit the term "low-risk endometrial carcinoma" to L1CAM-negative tumors [40]. While L1CAM protein expression has been connected to serous and clear cell histology as well as abnormal p53 status (subsequently correlating with worse outcome), there is also evidence suggesting a p53-independent L1CAM in endometrial carcinoma molecular subtypes [35,41-43]. Thus, L1CAM expression may help further stratify risk after molecular classification. However, while L1CAM-positive tumors clearly have worse outcomes, it is prudent to maintain the original TCGA tumor subgroups and to not consider L1CAM tumors a subtype but rather as a prognostic subgroup of the large p53 wild-type group with no specific molecular risk profile (NSMP) and perhaps of MMR-D tumors [44]. In summary, molecular classification as well as L1CAM immunohistochemistry will play a key role in future algorithms to tailor adjuvant treatment and patient follow-up strategies.

Future treatment strategies may include surgical considerations such as lymphonodectomy in low-risk endometrioid, FIGO stage Ia and G1/2 tumors if an integrated risk assessment indicates a rather unfavorable prognosis. Likewise, a modern integrated risk assessment will eventually help to identify patients in which more radical procedures such as systematic lymphonodectomy, omentectomy or multivisceral debulking attempts could contribute to longer progression-free survival (PFS) and overall survival times. Evaluation of adjuvant treatment modalities may be tailored to specific molecular features such as poly ADP ribose polymerase (PARP) inhibitors in p53 abnormal 
tumors, immune checkpoint inhibition or (chemo-)radiation in patients with a mismatch repair deficient (MMRd) subtype. Finally, patient follow-up might follow a less strict schedule and more cost-effective postoperative wait-and-see strategy if a bona fide low-risk situation is molecularly confirmed. In order to allow optimal upfront patient counseling, molecular profiling should be available at the time of endometrial biopsy.

\subsection{Current Recommendations for Adjuvant Treatment in Low-Risk Disease and Intermediate-Risk Parameters}

Guideline recommendations should be evidence-based. The comparability of the results from randomized trials in EC is limited, since different definitions of prognostic subgroups are used. The actual guidelines recommend no adjuvant treatment in low-risk disease and brachytherapy in patients with stage I and intermediate-risk parameters (see Figure 1). These guidelines are based on the classical risk factors according to Figure 1.

\subsubsection{Radiation Needed in Stage I?}

First-generation studies on adjuvant treatment demonstrated that, in stage I patients, external beam radiation decreases the pelvic and the vaginal recurrence rate significantly, but without impact on overall survival $[45,46]$. What always gets lost in the discussion about the value of stage I radiation therapy is the fact that overall survival was not the end point of the study. However, patients with grade 3 tumors and $>50 \%$ myometrial invasion achieved an improved survival rate after external body radiation therapy (EBRT) [4,46-48]. Subgroups of patients with conventionally defined high-intermediate risk parameters benefited in terms of survival. However, this was a strong indicator that patient selection for the adjuvant studies was problematic, based on what was known at the time. This kept the discussion alive, in which patients could benefit from more aggressive adjuvant therapy that could lead to the evaluation of chemotherapy for adjuvant treatment $[5,25]$.

\subsubsection{Radiation, Chemotherapy or Both: Who Could Profit?}

The second generation of adjuvant treatment studies in EC evaluated whether chemotherapy or radiation is superior. Three randomized trials evaluated the use of chemotherapy versus radiation in patients with intermediate- or high-risk disease, and two of them failed to show any benefit from chemotherapy over radiotherapy $[49,50]$. The randomized trial by Randall et al. (GOG-122) is the most cited and misunderstood study in this context [51]. In the study, researchers used doxorubicin $60 \mathrm{mg} / \mathrm{m}^{2}$ and cisplatin $50 \mathrm{mg} / \mathrm{m}^{2}$ every three weeks for seven cycles, followed by one cycle of cisplatin in women with FIGO stage III or IV endometrial carcinoma with a maximum of $2 \mathrm{~cm}$ of residual disease after surgery. This demonstrated better PFS when compared with patients who underwent a (not indicated) whole abdominal irradiation with insufficient doses [52]. Results should be interpreted with caution, since patients with palliative situations were treated with insufficient radiation doses versus chemotherapy combination with unacceptably high rates of late neurologic toxicity.

The third-generation studies considered that patients with clinical risk factors have both an increased risk of local recurrence and an increased risk of distant metastases. This study evaluated the simultaneous and sequential chemotherapy + radiation versus radiation.

The first third-generation study, the PORTEC-3 intergroup trial, investigated the potential benefit of concomitant chemoradiation followed by adjuvant chemotherapy versus pelvic radiotherapy alone for women with high risk for recurrence (FIGO stage I grade 3 with deep myometrial invasion LVSI, or both; stage II or III; or serous and clear cell histology). Six hundred and eighty-six women were randomly allocated to radiation (RT) with $48.6 \mathrm{~Gy}$ or chemoradiation (two cycles of concomitant cisplatin $50 \mathrm{mg} / \mathrm{m}^{2}$ in week one and week four of radiation, followed by four cycles of carboplatin AUC5 and paclitaxel $175 \mathrm{mg} / \mathrm{m}^{2}$ at three-week intervals (CRT-Ch)). Primary endpoints were overall survival (OS) and failure-free survival (FFS). After a median follow-up time of five years, five-year OS for CRT-Ch vs. RT was $81.8 \%$ versus $76.7 \%$, respectively (n.s.). Patients with stage III EC, which included IIIA, IIIB and an unknown correct number of stage IIIC1/2 had the greatest benefit from the 
combined treatment: five-year FFS for stage III was $69.3 \%$ for CRT-Ch versus $58.0 \%$ for RT ( $p=0.032$ ). In addition, patients $>70$ years with FIGO stage III, serous histology or both had a greater benefit in subgroup analyses $[18,53]$.

In contrast to PORTEC3, the GOG-258/NRG oncology study tested adjuvant chemotherapy alone versus chemoradiation. Patients with "optimally" debulked EC $(<2 \mathrm{~cm}$ residual tumor) were tested. Pelvic \pm paraaortic "lymph node sampling" was optional. Stage III/IVA endometrioid and FIGO stage I/II serous cancers were eligible and were assigned to either chemoradiation (EBRT $n=174$ or EBRT \pm brachytherapy with concomitant cisplatin $\left.50 \mathrm{mg} / \mathrm{m}^{2} \mathrm{~d} 1, \mathrm{~d} 29, n=204\right)$ followed by carboplatin AUC5 plus paclitaxel $175 \mathrm{mg} / \mathrm{m}^{2} \mathrm{q} 21 \times 4$ (CRT-Ch) versus chemotherapy only (Ch; carboplatin AUC6 and paclitaxel $175 \mathrm{mg} / \mathrm{m}^{2} \mathrm{q} 21 \times 6$ ) [54].

Chemoradiation halved the rates of pelvic and vaginal recurrences compared to chemotherapy (19\% versus $10 \%$ and $7 \%$ versus $3 \%$, respectively). Nevertheless, no difference in five-year OS was demonstrated. After five years, $21 \%$ and $27 \%$ of the patients after chemo and chemoradiation developed distant metastases [55].

The third, more recently published trial [56] was GOG-0249. This was an open-label phase III trial on the impact of recurrence-free survival (RFS) of EBRT (1.8/2.0 for 25-28 fractions) versus vaginal brachytherapy in combination with chemotherapy (paclitaxel at $175 \mathrm{mg} / \mathrm{m}^{2}$ followed by carboplatin AUC 6 over $45 \mathrm{~min}$ ), repeated every 21 days for three cycles (VCB/C) in women in FIGO stage I and high-intermediate risk criteria, stage II disease, or stage I to II serous or clear cell tumors. Consistent with the above-mentioned results of the GOG-258/NRG oncology study, EBRT reduced the rate of pelvic and paraaortic recurrences by $50 \%$ compared to chemotherapy and brachytherapy. As expected, vaginal recurrences were low $(2.5 \%)$ in both arms. Surprisingly, $18 \%$ of the patients developed distant metastases in both arms within five years.

\subsubsection{The Need for Additional Differentiation of EC to Predict Adjuvant Therapy}

In sum, recently published studies that should have provided clear evidence for the differentiated use of adjuvant therapies disappointed researchers with their partially contradictory results. The key to understanding the disappointing results is the inappropriate selection of patients based on clinical parameters. All included studies had a mixture of subgroups and cohorts that were biologically different. Patients benefited from the therapy to varying degrees; therefore, no consequences were clearly derived from the studies.

\subsection{Response Predicition for Chemotherapy and Radiation}

In addition to the prognostic value of genetic profiles, the question as to whether the genomic profile might have a predictive value for any adjuvant treatment is of great interest. Recently, Reijnen et al. were able to demonstrate MMRd molecular status as a predictive marker for response to adjuvant radiotherapy [57]. The authors were able to retrospectively investigate the predictive value of ProMisE MMR status within a large multicenter patient cohort of high-risk, stage IB or II grade 3 endometrioid endometrial carcinoma with and without adjuvant radiotherapy. Improved survival benefit was limited to patients with MMR-deficient tumor EECs (hazard ratio $0.19,95 \% \mathrm{CI}$ $0.05-0.77$ ), and thus MMR status may contribute to personalized patient selection criteria in a high-risk scenario $[57,58]$.

The radiosensitivity index (RSI) is a previously validated multigene expression index that estimates tumor radiosensitivity. Mohammadi et al. [59] validated the index in 204 patients with EC, of which $83(41 \%)$ were treated with adjuvant RT. The median follow-up was 38.5 months. In patients treated with radiation, radioresistant tumors showed a worsening three-year pelvic control ( $84 \%$ vs. $100 \%$; $p=0.02$ ) with a worsening progression-free survival (three-year PFFS $65 \%$ vs. $89 \% ; p=0.04$ ). More data are needed to derive a clinical implication. 


\subsection{New Study Landscape}

The PORTEC 4a Study, which is currently recruiting patients, is the first clinical trial applying molecular-integrated risk profiles in primary endometrial carcinoma patients. The PORTEC 4a study is a randomized trial of molecular-profile-based versus standard recommendations for adjuvant radiotherapy in women with early-stage endometrial cancer. The primary objective of this study is to establish the rates of vaginal relapse in patients with high-intermediate-risk endometrial carcinoma treated with vaginal brachytherapy based on clinicopathological (standard) indications and compare these rates with those of patients who have receive molecular risk profile based recommendations for vaginal brachytherapy, observation or external beam radiotherapy. While patients are treated with vaginal brachytherapy in the standard arm, treatment decisions are based on an integrated molecular risk classification in the experimental arm (2:1 randomization). Patients will either be observed after surgery and followed closely for vaginal recurrence (low molecular risk profile, POLE mutation or absence of MMRd and CTNNB1 exon 3 wild-type) or they will receive vaginal brachytherapy as mentioned above (intermediate molecular risk profile). If molecular risk assessment indicates a high-risk situation, patients are recommended external beam radiation instead of vaginal brachytherapy (p53 abnormal or L1CAM positivity or substantial lymphovascular space invasion [60]).

\subsection{New Guidelines for Adjuvant Treatment}

Due to the convincing data, the ESGO guideline committee decided to adapt the European guidelines on adjuvant treatment in endometrial cancer on the basis of new risk profiles (Table 1). The new guidelines will be published soon. A European proposal on new recommendations for adjuvant treatment is under discussion and will be published this year (Table 2).

Table 1. Upcoming ESGO and ESTRO recommendations on risk stratification after genomic classification (right) compared to clinical risk stratification (left).

\begin{tabular}{|c|c|c|}
\hline Risk Group & Molecular Classification Un-Known & Molecular Classification Known \\
\hline Low & $\begin{array}{l}\text { - } \quad \text { Stage IA Endometrioid + grade 1-2 + } \\
\text { LVSI negative }\end{array}$ & $\begin{array}{ll}- & \text { Stage I-III POLE mutant } \\
\text { - } & \text { Stage IA Endometrioid + grade 1-2 + } \\
& \text { LVSI negative }\end{array}$ \\
\hline Intermediate & $\begin{array}{l}\text { - Stage IB Endometrioid + grade 1-2 + } \\
\text { LVSI negative } \\
\text { Stage IA Endometrioid + grade } 3+ \\
\text { LVSI negative }\end{array}$ & $\begin{array}{l}\text { - } \quad \text { Stage IB Endometrioid + grade 1-2 + } \\
\text { LVSI negative MMRd or NSMP } \\
\text { - } \quad \text { Stage IA Endometrioid + grade } 3+ \\
\text { LVSI negative MMRd or NSMP }\end{array}$ \\
\hline High-Intermediate & $\begin{array}{l}\text { Stage I Endometrioid + substanial } \\
\text { LVSI, regardless of grade and depth } \\
\text { of invasion } \\
\text { - Stage IB Endometrioid grade 3, } \\
\text { regardless of LVSI status } \\
\text { - Stage II }\end{array}$ & $\begin{array}{ll}\text { - } & \text { Stage I Endometrioid + substantial } \\
\text { LVSI, regardless of grade and depth of } \\
\text { invasion, MMRd or NSMP } \\
\text { - } \\
\text { Stage IB Endometrioid grade 3, } \\
\text { regardless of LVSI status, MMRd } \\
\text { or NSMP } \\
\text { - } \quad \text { Stage II, MMRd or NSMP }\end{array}$ \\
\hline High & $\begin{array}{l}\text { - Stage III with no residual disease } \\
\text { Non endometrioid (serous, clear cell, } \\
\text { undifferentiated carcinoma, } \\
\text { carcinosarcoma, mixed) }\end{array}$ & $\begin{array}{l}\text { - } \quad \text { p53abn regardless of type or stage } \\
\text { Stage III Endometrioid with no } \\
\text { residual disease, MMRd or NSMP } \\
\text { Non endometrioid (serous, clear cell, } \\
\text { undifferentiated carcinoma, } \\
\text { carcinosarcoma, mixed) }\end{array}$ \\
\hline $\begin{array}{l}\text { Advanced } \\
\text { Metastatic }\end{array}$ & $\begin{array}{ll}\text { - } & \text { Stage III with residual disease \& IVA } \\
\text { - } & \text { Stage IVB }\end{array}$ & $\begin{array}{ll}\text { - } & \text { Stage III with residual disease \& IVA } \\
\text { - } & \text { Stage IVB }\end{array}$ \\
\hline
\end{tabular}


Table 2. Suggestions for future recommendations for adjuvant treatment according to the new risk stratification.

\begin{tabular}{|c|c|c|c|}
\hline \multirow{2}{*}{$\begin{array}{c}\text { New Risk Groups According } \\
\text { to Figure } 1\end{array}$} & \multicolumn{3}{|c|}{ Future Adjuvant Treatment Recommendations (Suggestions) } \\
\hline & Brachytherapy & External Beam Radiation & Chemotherapy \\
\hline Low Risk & no & no & no \\
\hline Intermediate Risk & yes & no & no \\
\hline $\begin{array}{l}\text { High-Intermediate Risk pN0 } \\
\text { (surgical staging or SLN neg.) }\end{array}$ & yes & If substantial LVSI & no \\
\hline $\begin{array}{c}\text { High-Intermediate Risk } \\
\text { cN0/pNX (no surgical staging } \\
\text { nor SLN) }\end{array}$ & yes & If substantial LVSI & $\begin{array}{l}\text { Especially for NSMP grade } 3 \\
\text { (see PORTEC3 protocol) }\end{array}$ \\
\hline $\begin{array}{c}\text { High Risk } \\
\text { p53+ regardless of stage; } \\
\text { stage IIIC1 NSMP/MMRd, no } \\
\text { residual tumor }\end{array}$ & no & $\begin{array}{r}\text { Concurrent che } \\
\text { (see POR } \\
\text { In case of contra-indications a }\end{array}$ & $\begin{array}{l}\text { adiation }+ \text { chemo } \\
3 \text { protocol) } \\
\text { sst chemo: EBRT recommended }\end{array}$ \\
\hline $\begin{array}{l}\text { High Risk } \\
\text { stage III C2 }\end{array}$ & no & $\begin{array}{r}\text { Extended } \\
\text { Concurrent che } \\
\text { (see POR } \\
\text { In case of contra-indications a }\end{array}$ & $\begin{array}{l}\text { d radiation: } \\
\text { adiation }+ \text { chemo } \\
3 \text { protocol) } \\
\text { nst chemo: EBRT recommended }\end{array}$ \\
\hline
\end{tabular}

\section{Conclusions}

The new insights into genomic classification open up new horizons for a better understanding of the biology of endometrial cancer, differentiated risk stratification, improved estimation of the prognosis and therapy response, de-escalation of adjuvant therapies for patients who do not benefit from them and escalation of adjuvant measures for patients with an aggressive illness. Recently, our group investigated if TCGA-inspired endometrial cancer molecular subtyping also stratifies the prognosis for a specific type of ovarian cancer (the endometrioid ovarian carcinoma) [61]. It could be demonstrated that four molecular subtypes, namely POLE mutant (POLEmut), mismatch repair deficient (MMRd), p53 abnormal (p53abn) and no specific molecular profile (NSMP), are independent factors for outcome and survival and could provide guidance in the future for individual treatment like fertility-sparing. The common goal in cancer treatment is to avoid unnecessary side effects and improve the prognosis. The PORTEC4 study has taken an important first step for the treatment of EC.

Author Contributions: Writing—original draft preparation, S.M., S.K. and S.Y.B.; writing—review and editing, S.M., T.W., B.S.-M., T.E., S.K., and S.Y.B. All authors have read and agreed to the published version of the manuscript.

Funding: This research received no external funding.

Conflicts of Interest: The authors declare no conflict of interest.

\section{References}

1. Bokhman, J.V. Two pathogenetic types of endometrial carcinoma. Gynecol. Oncol. 1983, 15, 10-17. [CrossRef]

2. Benedetti Panici, P.; Basile, S.; Salerno, M.G.; Di Donato, V.; Marchetti, C.; Perniola, G.; Palagiano, A.; Perutelli, A.; Maneschi, F.; Lissoni, A.A.; et al. Secondary analyses from a randomized clinical trial: Age as the key prognostic factor in endometrial carcinoma. Am. J. Obstet. Gynecol. 2014, 210, 363.e1-363.e10. [CrossRef]

3. Ureyen, I.; Karalok, A.; Turkmen, O.; Kimyon, G.; Akdas, Y.R.; Akyol, A.; Tasci, T.; Turan, T. Factors predicting recurrence in patients with stage IA endometrioid endometrial cancer: What is the importance of LVSI? Arch. Gynecol. Obstet. 2019, 301, 737-744. [CrossRef] [PubMed]

4. Keys, H.M.; Roberts, J.A.; Brunetto, V.L.; Zaino, R.J.; Spirtos, N.M.; Bloss, J.D.; Pearlman, A.; Maiman, M.A.; Bell, J.G.; Gynecologic Oncology Group. A phase III trial of surgery with or without adjunctive external pelvic radiation therapy in intermediate risk endometrial adenocarcinoma: A Gynecologic Oncology Group study. Gynecol. Oncol. 2004, 92, 744-751. [CrossRef] [PubMed] 
5. Colombo, N.; Creutzberg, C.; Amant, F.; Bosse, T.; Gonzalez-Martin, A.; Ledermann, J.; Marth, C.; Nout, R.; Querleu, D.; Mirza, M.R.; et al. ESMO-ESGO-ESTRO Consensus Conference on Endometrial Cancer: Diagnosis, Treatment and Follow-up. Int. J. Gynecol. Cancer 2016, 26. [CrossRef]

6. Mariani, A.; Webb, M.J.; Keeney, G.L.; Haddock, M.G.; Calori, G.; Podratz, K.C. Low-risk corpus cancer: Is lymphadenectomy or radiotherapy necessary? Am. J. Obstet. Gynecol. 2000, 182, 1506-1519. [CrossRef]

7. Morrow, C.P.; Bundy, B.N.; Homesley, H.D.; Creasman, W.T.; Hornback, N.B.; Kurman, R.; Thigpen, J.T. Doxorubicin as an Adjuvant Following Surgery and Radiation-Therapy in Patients with High-Risk Endometrial Carcinoma, Stage-I and Occult Stage-Ii: A Gynecologic Oncology Group-Study. Gynecol. Oncol. 1990, 36, 166-171. [CrossRef]

8. Mariani, A.; Webb, M.J.; Keeney, G.L.; Aletti, G.; Podratz, K.C. Assessment of prognostic factors in stage IIIA endometrial cancer. Gynecol. Oncol. 2002, 86, 38-44. [CrossRef]

9. Giglio, A.; Miller, B.; Curcio, E.; Kuo, Y.H.; Erler, B.; Bosscher, J.; Hicks, V.; ElSahwi, K. Challenges to Intraoperative Evaluation of Endometrial Cancer. J. Soc. Laparosc. Robot. Surg. 2020, 24. [CrossRef]

10. de Boer, S.M.; Wortman, B.G.; Bosse, T.; Powell, M.E.; Singh, N.; Hollema, H.; Wilson, G.; Chowdhury, M.N.; Mileshkin, L.; Pyman, J.; et al. Clinical consequences of upfront pathology review in the randomised PORTEC-3 trial for high-risk endometrial cancer. Ann. Oncol. 2017. [CrossRef]

11. Kumar, S.; Medeiros, F.; Dowdy, S.C.; Keeney, G.L.; Bakkum-Gamez, J.N.; Podratz, K.C.; Cliby, W.A.; Mariani, A. A prospective assessment of the reliability of frozen section to direct intraoperative decision making in endometrial cancer. Gynecol. Oncol. 2012, 127, 525-531. [CrossRef] [PubMed]

12. Grevenkamp, F.; Kommoss, F.; Kommoss, F.; Lax, S.; Fend, F.; Wallwiener, D.; Schonfisch, B.; Kramer, B.; Brucker, S.Y.; Taran, F.A.; et al. Second Opinion Expert Pathology in Endometrial Cancer: Potential Clinical Implications. Int. J. Gynecol. Cancer 2017, 27, 289-296. [CrossRef] [PubMed]

13. Morrow, C.P.; Bundy, B.N.; Kurman, R.J.; Creasman, W.T.; Heller, P.; Homesley, H.D.; Graham, J.E. Relationship between surgical-pathological risk factors and outcome in clinical stage I and II carcinoma of the endometrium: A Gynecologic Oncology Group study. Gynecol. Oncol. 1991, 40, 55-65. [CrossRef]

14. Panici, P.B.; Basile, S.; Maneschi, F.; Lissoni, A.A.; Signorelli, M.; Scambia, G.; Angioli, R.; Tateo, S.; Mangili, G.; Katsaros, D.; et al. Systematic Pelvic Lymphadenectomy vs No Lymphadenectomy in Early-Stage Endometrial Carcinoma: Randomized Clinical Trial. J. Natl. Cancer Inst. 2008, 100, 1707-1716. [CrossRef] [PubMed]

15. ASTEC Study Group; Kitchener, H.; Swart, A.M.; Qian, Q.; Amos, C.; Parmar, M.K. Efficacy of systematic pelvic lymphadenectomy in endometrial cancer (MRC ASTEC trial): A randomised study. Lancet 2009, 373, 125-136. [CrossRef]

16. Naumann, R.W. The role of lymphadenectomy in endometrial cancer: Was the ASTEC trial doomed by design and are we destined to repeat that mistake? Gynecol. Oncol. 2012, 126, 5-11. [CrossRef]

17. Creasman, W.T.; Mutch, D.E.; Herzog, T.J. ASTEC lymphadenectomy and radiation therapy studies: Are conclusions valid? Gynecol. Oncol. 2010, 116, 293-294. [CrossRef]

18. de Boer, S.M.; Powell, M.E.; Mileshkin, L.; Katsaros, D.; Bessette, P.; Haie-Meder, C.; Ottevanger, P.B.; Ledermann, J.A.; Khaw, P.; Colombo, A.; et al. Adjuvant chemoradiotherapy versus radiotherapy alone for women with high-risk endometrial cancer (PORTEC-3): Final results of an international, open-label, multicentre, randomised, phase 3 trial. Lancet Oncol. 2018, 19, 295-309. [CrossRef]

19. Plante, M.; Stanleigh, J.; Renaud, M.C.; Sebastianelli, A.; Grondin, K.; Gregoire, J. Isolated tumor cells identified by sentinel lymph node mapping in endometrial cancer: Does adjuvant treatment matter? Gynecol. Oncol. 2017, 146, 240-246. [CrossRef]

20. Ignatov, A.; Lebius, C.; Ignatov, T.; Ivros, S.; Knueppel, R.; Papathemelis, T.; Ortmann, O.; Eggemann, H. Lymph node micrometastases and outcome of endometrial cancer. Gynecol. Oncol. 2019, 154, 475-479. [CrossRef]

21. Piedimonte, S.; Richer, L.; Souhami, L.; Arseneau, J.; Fu, L.; Gilbert, L.; Alfieri, J.; Jardon, K.; Zeng, X.Z. Clinical significance of isolated tumor cells and micrometastasis in low-grade, stage I endometrial cancer. J. Surg. Oncol. 2018, 118, 1194-1198. [CrossRef]

22. Gomez-Hidalgo, N.R.; Ramirez, P.T.; Ngo, B.; Perez-Hoyos, S.; Coreas, N.; Sanchez-Iglesias, J.L.; Cabrera, S.; Franco, S.; Benavente, A.P.; Gil-Moreno, A. Oncologic impact of micrometastases or isolated tumor cells in sentinel lymph nodes of patients with endometrial cancer: A meta-analysis. Clin. Transl. Oncol. 2019. [CrossRef] [PubMed] 
23. Todo, Y.; Kato, H.; Okamoto, K.; Minobe, S.; Yamashiro, K.; Sakuragi, N. Isolated tumor cells and micrometastases in regional lymph nodes in stage I to II endometrial cancer. J. Gynecol. Oncol. 2016, 27, e1. [CrossRef] [PubMed]

24. Rossi, E.C.; Kowalski, L.D.; Scalici, J.; Cantrell, L.; Schuler, K.; Hanna, R.K.; Method, M.; Ade, M.; Ivanova, A.; Boggess, J.F. A comparison of sentinel lymph node biopsy to lymphadenectomy for endometrial cancer staging (FIRES trial): A multicentre, prospective, cohort study. Lancet Oncol. 2017, 18, 384-392. [CrossRef]

25. Ballester, M.; Bendifallah, S.; Darai, E. European guidelines (ESMO-ESGO-ESTRO consensus conference) for the management of endometrial cancer. Bull. Cancer 2017, 104, 1032-1038. [CrossRef]

26. Kapucuoglu, N.; Bulbul, D.; Tulunay, G.; Temel, M.A. Reproducibility of grading systems for endometrial endometrioid carcinoma and their relation with pathologic prognostic parameters. Int. J. Gynecol. Cancer Off. J. Int. Gynecol. Cancer Soc. 2008, 18, 790-796. [CrossRef]

27. Clarke, B.A.; Gilks, C.B. Endometrial carcinoma: Controversies in histopathological assessment of grade and tumour cell type. J. Clin. Pathol. 2010, 63, 410-415. [CrossRef]

28. Gilks, C.B.; Oliva, E.; Soslow, R.A. Poor inter-observer reproducibility in the diagnosis of high-grade endometrial carcinoma. Am. J. Surg. Pathol. 2012, 91, 248A.

29. Guan, H.; Semaan, A.; Bandyopadhyay, S.; Arabi, H.; Feng, J.; Fathallah, L.; Pansare, V.; Qazi, A.; Abdul-Karim, F.; Morris, R.T.; et al. Prognosis and reproducibility of new and existing binary grading systems for endometrial carcinoma compared to FIGO grading in hysterectomy specimens. Int. J. Gynecol. Cancer Off. J. Int. Gynecol. Cancer Soc. 2011, 21, 654-660. [CrossRef]

30. Han, G.; Sidhu, D.; Duggan, M.A.; Arseneau, J.; Cesari, M.; Clement, P.B.; Ewanowich, C.A.; Kalloger, S.E.; Kobel, M. Reproducibility of histological cell type in high-grade endometrial carcinoma. Mod. Pathol. 2013, 26, 1594-1604. [CrossRef]

31. Talhouk, A.; McConechy, M.K.; Leung, S.; Li-Chang, H.H.; Kwon, J.S.; Melnyk, N.; Yang, W.; Senz, J.; Boyd, N.; Karnezis, A.N.; et al. A clinically applicable molecular-based classification for endometrial cancers. Br. J. Cancer 2015, 113, 299-310. [CrossRef] [PubMed]

32. Kommoss, S.; McConechy, M.K.; Kommoss, F.; Leung, S.; Bunz, A.; Magrill, J.; Britton, H.; Kommoss, F.; Grevenkamp, F.; Karnezis, A.; et al. Final validation of the ProMisE molecular classifier for endometrial carcinoma in a large population-based case series. Ann. Oncol. 2018, 29, 1180-1188. [CrossRef] [PubMed]

33. Stelloo, E.; Nout, R.A.; Osse, E.M.; Jurgenliemk-Schulz, I.J.; Jobsen, J.J.; Lutgens, L.C.; van der Steen-Banasik, E.M.; Nijman, H.W.; Putter, H.; Bosse, T.; et al. Improved Risk Assessment by Integrating Molecular and Clinicopathological Factors in Early-stage Endometrial Cancer-Combined Analysis of the PORTEC Cohorts. Clin. Cancer Res. 2016, 22, 4215-4224. [CrossRef]

34. Stelloo, E.; Bosse, T.; Nout, R.A.; MacKay, H.J.; Church, D.N.; Nijman, H.W.; Leary, A.; Edmondson, R.J.; Powell, M.E.; Crosbie, E.J.; et al. Refining prognosis and identifying targetable pathways for high-risk endometrial cancer; a TransPORTEC initiative. Mod. Pathol. 2015, 28, 836-844. [CrossRef]

35. Zeimet, A.G.; Reimer, D.; Huszar, M.; Winterhoff, B.; Puistola, U.; Azim, S.A.; Muller-Holzner, E.; Ben-Arie, A.; van Kempen, L.C.; Petru, E.; et al. L1CAM in early-stage type I endometrial cancer: Results of a large multicenter evaluation. J. Natl. Cancer Inst. 2013, 105, 1142-1150. [CrossRef] [PubMed]

36. Altevogt, P.; Doberstein, K.; Fogel, M. L1CAM in human cancer. Int. J. Cancer 2015. [CrossRef] [PubMed]

37. Bosse, T.; Nout, R.A.; Stelloo, E.; Dreef, E.; Nijman, H.W.; Jurgenliemk-Schulz, I.M.; Jobsen, J.J.; Creutzberg, C.L.; Smit, V.T. L1 cell adhesion molecule is a strong predictor for distant recurrence and overall survival in early stage endometrial cancer: Pooled PORTEC trial results. Eur. J. Cancer 2014, 50, 2602-2610. [CrossRef] [PubMed]

38. Dellinger, T.H.; Smith, D.D.; Ouyang, C.; Warden, C.D.; Williams, J.C.; Han, E.S. L1CAM is an independent predictor of poor survival in endometrial cancer-An analysis of The Cancer Genome Atlas (TCGA). Gynecol. Oncol. 2016, 141, 336-340. [CrossRef] [PubMed]

39. van der Putten, L.J.; Visser, N.C.; van de Vijver, K.; Santacana, M.; Bronsert, P.; Bulten, J.; Hirschfeld, M.; Colas, E.; Gil-Moreno, A.; Garcia, A.; et al. L1CAM expression in endometrial carcinomas: An ENITEC collaboration study. Br. J. Cancer 2016, 115, 716-724. [CrossRef]

40. Kommoss, F.; Kommoss, F.; Grevenkamp, F.; Bunz, A.K.; Taran, F.A.; Fend, F.; Brucker, S.Y.; Wallwiener, D.; Schonfisch, B.; Greif, K.; et al. L1CAM: Amending the "low-risk" category in endometrial carcinoma. J. Cancer Res. Clin. Oncol. 2017, 143, 255-262. [CrossRef] 
41. Fogel, M.; Gutwein, P.; Mechtersheimer, S.; Riedle, S.; Stoeck, A.; Smirnov, A.; Edler, L.; Ben-Arie, A.; Huszar, M.; Altevogt, P. L1 expression as a predictor of progression and survival in patients with uterine and ovarian carcinomas. Lancet 2003, 362, 869-875. [CrossRef]

42. Karnezis, A.N.; Leung, S.; Magrill, J.; McConechy, M.K.; Yang, W.; Chow, C.; Kobel, M.; Lee, C.H.; Huntsman, D.G.; Talhouk, A.; et al. Evaluation of endometrial carcinoma prognostic immunohistochemistry markers in the context of molecular classification. J. Pathol. Clin. Res. 2017, 3, 279-293. [CrossRef]

43. Van Gool, I.C.; Stelloo, E.; Nout, R.A.; Nijman, H.W.; Edmondson, R.J.; Church, D.N.; MacKay, H.J.; Leary, A.; Powell, M.E.; Mileshkin, L.; et al. Prognostic significance of L1CAM expression and its association with mutant p53 expression in high-risk endometrial cancer. Mod. Pathol. 2016, 29, 174-181. [CrossRef]

44. Kommoss, F.K.; Karnezis, A.N.; Kommoss, F.; Talhouk, A.; Taran, F.A.; Staebler, A.; Gilks, C.B.; Huntsman, D.G.; Kramer, B.; Brucker, S.Y.; et al. L1CAM further stratifies endometrial carcinoma patients with no specific molecular risk profile. Br. J. Cancer 2018, 119, 480-486. [CrossRef]

45. Aalders, J.; Abeler, V.; Kolstad, P.; Onsrud, M. Postoperative external irradiation and prognostic parameters in stage I endometrial carcinoma: Clinical and histopathologic study of 540 patients. Obstet. Gynecol. 1980, $56,419-427$.

46. Creutzberg, C.L.; Nout, R.A.; Lybeert, M.L.; Warlam-Rodenhuis, C.C.; Jobsen, J.J.; Mens, J.W.; Lutgens, L.C.; Pras, E.; van de Poll-Franse, L.V.; van Putten, W.L.; et al. Fifteen-year radiotherapy outcomes of the randomized PORTEC-1 trial for endometrial carcinoma. Int. J. Radiat. Oncol. Biol. Phys. 2011, 81, e631-e638. [CrossRef]

47. Kong, A.; Johnson, N.; Kitchener, H.C.; Lawrie, T.A. Adjuvant Radiotherapy for Stage I Endometrial Cancer: An Updated Cochrane Systematic Review and Meta-analysis. J. Natl. Cancer Inst. 2012, 104, 1625-1634. [CrossRef]

48. Creutzberg, C.L.; van Putten, W.L.; Koper, P.C.; Lybeert, M.L.; Jobsen, J.J.; Warlam-Rodenhuis, C.C.; De Winter, K.A.; Lutgens, L.C.; van den Bergh, A.C.; van de Steen-Banasik, E.; et al. Surgery and postoperative radiotherapy versus surgery alone for patients with stage-1 endometrial carcinoma: Multicentre randomised trial. PORTEC Study Group. Post Operative Radiation Therapy in Endometrial Carcinoma. Lancet 2000, 355, 1404-1411. [CrossRef]

49. Maggi, R.; Lissoni, A.; Spina, F.; Melpignano, M.; Zola, P.; Favalli, G.; Colombo, A.; Fossati, R. Adjuvant chemotherapy vs radiotherapy in high-risk endometrial carcinoma: Results of a randomised trial. Br. J. Cancer 2006, 95, 266-271. [CrossRef] [PubMed]

50. Susumu, N.; Sagae, S.; Udagawa, Y.; Niwa, K.; Kuramoto, H.; Satoh, S.; Kudo, R.; Japanese Gynecologic Oncology, G. Randomized phase III trial of pelvic radiotherapy versus cisplatin-based combined chemotherapy in patients with intermediate- and high-risk endometrial cancer: A Japanese Gynecologic Oncology Group study. Gynecol. Oncol. 2008, 108, 226-233. [CrossRef]

51. Randall, M.E.; Spirtos, N.M.; Dvoretsky, P. Whole abdominal radiotherapy versus combination chemotherapy with doxorubicin and cisplatin in advanced endometrial carcinoma (phase III): Gynecologic Oncology Group Study No. 122. J. Natl. Cancer Inst. Monogr. 1995, 19, 13-15.

52. Randall, M.E.; Filiaci, V.L.; Muss, H.; Spirtos, N.M.; Mannel, R.S.; Fowler, J.; Thigpen, J.T.; Benda, J.A.; Gynecologic Oncology Group Study. Randomized phase III trial of whole-abdominal irradiation versus doxorubicin and cisplatin chemotherapy in advanced endometrial carcinoma: A Gynecologic Oncology Group Study. J. Clin. Oncol. 2006, 24, 36-44. [CrossRef]

53. de Boer, S.M.; Powell, M.E.; Mileshkin, L.; Katsaros, D.; Bessette, P.; Haie-Meder, C.; Ottevanger, P.B.; Ledermann, J.A.; Khaw, P.; Colombo, A.; et al. Toxicity and quality of life after adjuvant chemoradiotherapy versus radiotherapy alone for women with high-risk endometrial cancer (PORTEC-3): An open-label, multicentre, randomised, phase 3 trial. Lancet Oncol. 2016, 17, 1114-1126. [CrossRef]

54. Matei, D.; Filiaci, V.; Randall, M.E.; Mutch, D.; Steinhoff, M.M.; DiSilvestro, P.A.; Moxley, K.M.; Kim, Y.M.; Powell, M.A.; O'Malley, D.M.; et al. Adjuvant Chemotherapy plus Radiation for Locally Advanced Endometrial Cancer. N. Engl. J. Med. 2019, 380, 2317-2326. [CrossRef]

55. Matei, D.; Filiaci, V.L.; Randall, M.; Steinhoff, M.; DiSilvestro, P.; Moxley, K.M.; Kim, B.; Powell, M.A.; O'Malley, D.M.; Spirtos, N.M.; et al. A randomized phase III trial of cisplatin and tumor volume directed irradiation followed by carboplatin and paclitaxel vs. carboplatin and paclitaxel for optimally debulked, advanced endometrial carcinoma. J. Clin. Oncol. 2017, 35, 5505. [CrossRef] 
56. Randall, M.E.; Filiaci, V.; McMeekin, D.S.; von Gruenigen, V.; Huang, H.; Yashar, C.M.; Mannel, R.S.; Kim, J.W.; Salani, R.; DiSilvestro, P.A.; et al. Phase III Trial: Adjuvant Pelvic Radiation Therapy Versus Vaginal Brachytherapy Plus Paclitaxel/Carboplatin in High-Intermediate and High-Risk Early Stage Endometrial Cancer. J. Clin. Oncol. 2019, 37, 1810-1818. [CrossRef]

57. Reijnen, C.; Kusters-Vandevelde, H.V.N.; Prinsen, C.F.; Massuger, L.F.; Snijders, M.P.; Kommoss, S.; Brucker, S.Y.; Kwon, J.S.; McAlpine, J.N.; Pijnenborg, J.M.A. Mismatch repair deficiency as a predictive marker for response to adjuvant radiotherapy in endometrial cancer. Gynecol. Oncol. 2019, 154, 124-130. [CrossRef]

58. Van Gool, I.C.; Rayner, E.; Osse, E.M.; Nout, R.A.; Creutzberg, C.L.; Tomlinson, I.P.M.; Church, D.N.; Smit, V.; de Wind, N.; Bosse, T.; et al. Adjuvant Treatment for POLE Proofreading Domain-Mutant Cancers: Sensitivity to Radiotherapy, Chemotherapy, and Nucleoside Analogues. Clin. Cancer Res. 2018, 24, 3197-3203. [CrossRef]

59. Mohammadi, H.; Prince, A.; Figura, N.B.; Peacock, J.S.; Fernandez, D.C.; Montejo, M.E.; Chon, H.S.; Wenham, R.M.; Eschrich, S.A.; Torres-Roca, J.F.; et al. Using the Radiosensitivity Index (RSI) to Predict Pelvic Failure in Endometrial Cancer Treated With Adjuvant Radiation Therapy. Int. J. Radiat. Oncol. Biol. Phys. 2020, 106, 496-502. [CrossRef]

60. Wortman, B.G.; Bosse, T.; Nout, R.A.; Lutgens, L.; van der Steen-Banasik, E.M.; Westerveld, H.; van den Berg, H.; Slot, A.; De Winter, K.A.J.; Verhoeven-Adema, K.W.; et al. Molecular-integrated risk profile to determine adjuvant radiotherapy in endometrial cancer: Evaluation of the pilot phase of the PORTEC-4a trial. Gynecol. Oncol. 2018, 151, 69-75. [CrossRef]

61. Krämer, P.; Talhouk, A.; Brett, M.A.; Chiu, D.S.; Cairns, E.S.; Scheunhage, D.A.; Hammond, R.F.; Farnell, D.; Nazeran, T.M.; Grube, M.; et al. Endometrial Cancer Molecular Risk Stratification is Equally Prognostic for Endometrioid Ovarian Carcinoma. Clin. Cancer Res. 2020. [CrossRef]

(C) 2020 by the authors. Licensee MDPI, Basel, Switzerland. This article is an open access article distributed under the terms and conditions of the Creative Commons Attribution (CC BY) license (http://creativecommons.org/licenses/by/4.0/). 